\title{
"SOB A MALDIÇÃO DE CAIM": HISTÓRIA DE VIDA NAS IMIGRAÇÕES CONTEMPORÂNEAS EM SÃO PAULO
}

\author{
“UNDER THE CURSE OF CAIN": STORY OF LIFE IN CONTEMPORARY \\ IMMIGRATION IN SÃO PAULO
}

\begin{abstract}
Claudia Moraes Souza
Professora Doutora Adjunta da UNIFESP, Campus Osasco, desde 2013. Professora da Pós Graduação Interdisciplinar "Humanidades, Direitos e outras Legitimidades" do Diversitas/USP desde 2012. Historiadora . Autora dos livros "Movimentos Sociais no Brasil Contemporâneo" da Editora Loyola e " Pelas Ondas do Rádio : Camponeses, Cultura Popular e o rádio nos anos de 1960" da Editora Alameda. Experiência de pesquisa em temas que se interseccionam aos Estudos Culturais e ao debate das relações Estado e

Sociedade Civil no Brasil, com foco na interação entre atores sociais e instituições políticas. Estuda a temática dos movimentos sociais , resistências culturais, imigrantes contemporâneos,organizações políticas e participação popular. E-mail: cacamoraes.history@gmail.com
\end{abstract}

Convidada

Doi: $10.5585 /$ rdb.v17i7.629

\begin{abstract}
RESUMO: Neste artigo analisamos um caso específico de tráfico internacional de pessoas e todo o processo de reestruturação da vida social de uma imigrante laboral em São Paulo/Brasil. Tendo por base metodológica a história oral, mais especificamente a história de vida, desvendamos a dimensão individual, cotidiana e particular da experiência de um sujeito, sem deixar de observála pelo paradigma histórico-estrutural, que envolve, na cidade de São Paulo, a reorganização da indústria têxtil e o tráfico internacional de pessoas para o trabalho degradante ou escravo. Apontamos que a imigração laboral se constitui como um fato duplo, primeiro porque articula o indivíduo ao coletivo compondo-se de elementos do tempo histórico-estrutural da globalização da produção. Segundo, indicando que, a luta pelo direito à cidade e pelos direitos humanos é o elemento central da sobrevivência do sujeito deslocado, que, no caso analisado se tornou sujeito de uma luta política pela conquista de direitos que envolvem a efetivação dos direitos sociais e humanos: desde o direito à liberdade e ao trabalho decente, até o direito à educação, moradia, ao lazer e à convivência democrática no território em que decidiu viver e trabalhar.
\end{abstract}

Palavras-chaves: Imigração-História de Vida-Direitos Humanos

\begin{abstract}
This article has the goal to analyze the current international relations according the labor migrations. Approaching concepts of the economical system, the global capital structure and the structural unemployment we analyze questions about daily life and survival of the international immigrant workers. The methodology put into practice was the Oral History, which made possible the understanding of the subjective, quotidian and particularly dimensions of the labor migrations, also observing the historical and structural paradigm in which the textile industry in Brazil is involved together with the international traffic of peoples to the slave labor.
\end{abstract}

Keyword : Immigration-life's history-human rights 
SUMÁRIO: Introdução: A Maldição de Caim; Filhas de Eva na Maldição de Caim; A História de Eliza; Referências Bibliográficas

\section{INTRODUÇÃO: A MALDIÇÃO DE CAIM}

[...]Então, não serei castigado pelo meu crime, perguntou Caim, A minha porção de culpa não absolve a tua, terás o teu castigo, Qual andarás errante e perdido pelo mundo, Sendo assim, qualquer pessoa me poderá matar, Não, porque porei um sinal na tua testa, ninguém te fará mal, Mas, em pago da minha benevolência, procura tu não fazer mal a ninguém, disse o senhor tocando com o dedo indicador a testa de Caim, onde apareceu uma pequena mancha [...] (Saramago,2009, p.36)

Em sua reinvenção heterodoxa do Antigo Testamento, no livro Caim, Saramago recria de forma sui generis seus protagonistas e suas principais mazelas. Na prosa irônica e ácida, o autor apresenta uma nova leitura do texto religioso, revelando seu olhar crítico a tudo que está oculto nos dilemas e agruras de tão conhecidos personagens. Caim, marcado pela mão divina, foi condenado a vagar pelos continentes, andar errante, sem lar e sem pátria. A marca de Caim definiu seu destino e tornou presente, no mito, o desenraizamento como forma de castigo.

O personagem literário de Saramago construído a partir do mito de Caim nos apresenta uma alegoria para a identificação do sujeito deslocado. Um sujeito itinerante, forçado à transumância constante, onde a condição de existência se encontra fundada, ela mesma, no deslocamento, na diáspora e na migração. Como Thompson identificou a maldição de Adão como alegoria possível na identificação da classe trabalhadora inglesa em sua formação, condenada a obter sua sobrevivência a partir do suor de seu rosto e do trabalho árduo de suas mãos, a maldição de Caim aqui tomada como alegoria, denota a identificação de um sujeito cada vez mais presente na contemporaneidade, o imigrante internacional, submetido a uma condição duplamente frágil: aquela vinculada à necessidade do trabalho como forma de sobrevivência, e aquela vinculada a necessidade de deslocamento constante no território em busca de trabalho.

Desta forma, o tempo premido por uma globalização marcada pela hegemonia do capital e do mercado, sobre todo e qualquer aspecto da vida humana, nos apresenta a condição do sujeito deslocado de seu lugar de origem pelas necessidades da produção, como uma figura cada vez mais constante e presente na cena mundial. Dois fenômenos marcam as características da Nova Ordem Mundial no tempo imediato: primeiro, a Globalização, como fenômeno crescente do processo de internacionalização da economia, predomínio do mercado e superdimensionamento da expansão do capital, e, segundo, a Imigração Laboral, como fenômeno decorrente de transformações produtivas e nova organização do trabalho levado à condição de trabalho móvel.

Neste tempo configuram-se e articulam-se os fenômenos do global e do local revelando as necessidades múltiplas do capital em se reconfigurar constantemente, exigindo do trabalho a constante mudança, a realocação, o deslocamento físico e espacial, o reordenamento e a requalificação. Transformam-se, constantemente, o espaço e as formas de produção afirmando cruelmente a inconstância na vida do trabalhador.

Partindo do contexto do sistema econômico, da estruturação do capital em dimensão global, do desemprego estrutural e suas consequências para a sobrevivência da mão de obra, tomando como referência o sujeito da migração laboral, optamos por construir uma investigação que possibilitou-nos fundir dimensões estruturais às múltiplas dimensões da vida dos sujeitos do trabalho. Tomando por base a história de vida chamamos a atenção à dimensão individual, cotidiana e particular da migração laboral, sem deixar de observá-la pelo paradigma históricoestrutural e humanístico.

Sob a perspectiva de uma teoria histórico-estrutural, que colaborou sensivelmente com a teoria das migrações, a contemporaneidade tem afirmado a associação entre o mercado de

Revista de Direito Brasileira | São Paulo, SP | v. 17 | n. 7 | p. 154 - 164 | Mai./Ago. 2017 
trabalho e o movimento de pessoas. Pelos estudos de Saskia Sassen (2008), passamos a compreender e problematizar as cidades globais como grandes espaços da internacionalização do capital e reprodução de seus circuitos. Propondo a releitura das representações do espaço da cidade global, a autora revelou a formação de centros para onde convergem as várias formas da economia global: como a imigração laboral, o circuito econômico informal, novos regimes de trabalho, criação dos espaços eletrônicos e midiáticos responsáveis pelos novos desenhos do cotidiano desta cidade.

Em E.P.Thompson (1988), no século XVIII a presença ameaçadora da fábrica, tecida pela revolução Industrial, se impôs como a maldição de Adão entre os trabalhadores, submetidos à exploração pelo trabalho, a nova configuração do tempo social, ao controle dos corpos e oprimidos pela política e pela cultura da classe dominante. Na internacionalização do capital, no espaço da cidade global analisada por Sassen (2008), a submissão ao trabalho se reconfigura na maldição de Caim, marcada pela transumância, pela mobilidade constante, de forma que, o sujeito do trabalho só se mantém ativo, na medida em que, se desloca aos novos postos laborais ofertados na produção transnacional.

Destarte, o reconhecimento da articulação sistêmica do capital, e, do papel da fábrica na submissão e disciplinarização da força de trabalho, a experiência fabril foi analisada por Thompson (1988) em múltiplas dimensões, principalmente, no que tange a reconstrução das condições sociais de reprodução da vida de homens, mulheres e crianças na Inglaterra setecentista. Apesar de a fábrica haver estabelecido uma revolução nos hábitos e costumes do trabalho, no sentido de discipliná-lo e enquadrá-lo a lógica do tempo do capital, a preocupação do autor foi a de compreender as experiências dos sujeitos no interior da fábrica e principalmente fora delas. Nesta perspectiva teórica, para além do entendimento histórico estrutural, configuramse preceitos teóricos ligados à experiência social dos sujeitos, tornando possível uma teoria que articule estudos voltados à compreensão das dimensões estruturais do capital sem perder de vista a reflexão da condição dos sujeitos históricos.

Neste artigo propomos a discussão da imigração laboral internacional buscando uma perspectiva articulada entre o fenômeno da transnacionalização do trabalho, o que envolve diretamente a imigração laboral, e o conjunto de experiências sociais dos sujeitos do trabalho internacionalizado.

Sob orientações teóricas de Abdelmalek Sayad (1998), a imigração, como fenômeno do tempo social, se constitui em um fenômeno global que envolve o fato coletivo e o fato individual concomitantemente. Ou seja, a imigração laboral, pautada pela necessidade sistêmica ou estrutural da sobrevivência do sujeito como força de trabalho, se constitui como um fato duplo: que articula o indivíduo ao coletivo, compondo-se de elementos do tempo histórico em suas dimensões culturais, políticas, econômicas, dentre outas.

Tratar do fenômeno das migrações laborais significa explorar simultaneamente as dimensões globais da produção e reprodução do capital internacionalizado revelando que a imigração internacional se constituiu em componente chave da produção da mercadoria e da reprodução social do trabalho, mas significa também, entender e revelar questões do sujeito deslocado, no sentido de devolver ao fenômeno um sentido de fato social total. Segundo Sayad (1998), as teorias sociológicas dos anos 70 e 80, que exploraram o fenômeno migratório, optaram por uma visão panorâmica e sistêmica, que condicionavam os sujeitos à massificação - imigrantes pensados como grandes massas em deslocamento. Como desafio do tempo atual, no estudo das migrações contemporâneas, temos a construção de teorias sociológicas e históricas voltadas para o entendimento do sujeito em deslocamento, tendo como objetivos pensá-los em suas múltiplas dimensões (cultural, religiosa, cotidiana e política).

$\mathrm{O}$ fenômeno migratório representado na totalidade sistêmica se prende à lógica do Estado Nacional e acaba por constituir a representação clássica do trabalhador deslocado como um constante incômodo social. O deslocamento de um conjunto amplo de indivíduos, aquilo que 
nos estudos demográficos se condiz chamar de "corredor migratório", produz a situação constante do provisório, do desamparo, de inconstitucionalidade, de ambiguidade e de dissimulação, principalmente, no campo que se refere às convenções dos direitos nacionais. $\mathrm{O}$ imigrante, na sociedade de acolhida, apresenta necessidades de sua condição humana, gerando demandas por serviços básicos múltiplos. Tendencialmente, na sociedade de acolhida, este sujeito passa a ser visto e tratado como um problema. Tradicionalmente as populações locais ou nacionais rechaçam as políticas imigratórias e a acolhida à imigrantes e cobram do Estado o controle migratório, ficando este sobre a ameaça de múltiplos problemas: garantir força de trabalho ao capital, controlar fronteiras, estar atento à acolhida do imigrante e responder acerca de direitos humanos da comunidade imigrada frente aos organismos.

Um imigrante, na definição de Sayad (1998), assume assim uma multiplicidade de dimensões. Sob a ótica da sociedade que o recebe, pode definir-se como um problema a ser resolvido. Sob a ótica do Estado Nacional, ele é na maioria das vezes um "mal necessário", na garantia da produção. Sob a ótica do país de saída, ele é um "Emigrante", situação espectral (quase fantasmagórica), em que, mesmo ausente, ele se faz presente como um cidadão nacional apresentando demandas que se efetivam em outro território. Sob a perspectiva individual, ele é um sujeito ausente em seu núcleo familiar, sua terra, suas referências culturais, ao mesmo tempo em que, presente em novos espaços como elemento provocador do contato intercultural, das negociações culturais e, acima de tudo, do difícil movimento de acolhida e integração, como aceitação e reconhecimento.

\section{FILHAS DE EVA NA MALDIÇÃO DE CAIM}

Agora, tratando das novas dimensões da imigração internacional e das particularidades dos sujeitos da imigração cabe considerar novos perfis dos sujeitos. Desde meados do século XXI, a mulher tem sido um agente central nas migrações e o número de mulheres imigrantes tem aumentado passando a representar, segundo a Organização Internacional do Trabalho-OIM, cerca de metade dos imigrantes em todo o mundo. Este aumento, revela que o padrão tradicional de imigração - primeiro migrar o homem e só depois a mulher e os filhos - mudou radicalmente e as mulheres passam a migrar sozinhas ou optam por acompanhar o marido, deixando os filhos nos países de origem.

Na imigração laboral, as trabalhadoras são frequentemente encaminhadas para o trabalho doméstico e de prestação de cuidados, sectores invisíveis em que muitas vezes não estão protegidas pela legislação laboral no país de destino. Ou ainda, claramente no caso brasileiro, para o trabalho em condições degradantes e o trabalho escravo, engrossando as fileiras de trabalhadores e as situações que elevam os números de casos de exploração, abusos e infração dos direitos humanos. As trabalhadoras migrantes podem acumular numerosos níveis de discriminação que interligam as questões de gênero com às questões culturais e da exploração do trabalho: discriminação cultural, de etnia, nacionalidade, religião, salarial, dentre muitos.

Desta forma, a mulher se torna um sujeito da imigração com qualidades específicas e de dupla possibilidade, primeiro apresentando questões da condição feminina que a fragilizam no processo exploratório, como dito anteriormente, e, as qualidades específicas da incorporação da mulher no trabalho, contribuindo para o reforço das capacidades das mulheres, que assim adquirem novas qualificações, mais autoestima e independência econômica, vinculação com o novo território propiciando formação de redes, associações e movimentos sociais de uma maneira geral.

Este artigo foi construído a partir desta ideia. A ideia de mulheres imigrantes como sujeito específico do processo imigratório internacional, dotado de matizes próprias. Nuances que merecem um olhar apurado sobre sua condição de invisibilidade social, ao mesmo tempo em que se perceba a potencialidade de ação e organização do sujeito feminino no todo social. A história 
oral e de vida foi nossa opção metodológica para fazer vir à tona a narrativa destes sujeitos e principalmente as reflexões e o exercício epistemológico e percepção da própria história pessoal que os sujeitos realizam no processo de narrar, relembrar e recompor em narrativa a sua história de vida.

Apresentamos nesta transcriação, a história de nossa colaboradora recomposta como sujeito e objeto da história do tempo presente, com foco no estabelecimento do sujeito em sua complexidade individual e preocupada com o desvendamento dos fatos sociais individuais e coletivos, diante do fenômeno migratório internacional contemporâneo. Estas questões teóricometodológicas se opõem à representação sistêmica da imigração como fenômeno global e de massa e da representação do imigrante como problema social e nacional, nossa busca pretende encontrar sujeitos históricos, sua dimensão de indivíduo, sua história de vida, seus dilemas cotidianos e suas expectativas de direitos. Estas perspectivas aparecem como elementos presentes na história das migrações contemporâneas imprimindo aos estudos das migrações as preocupações com a interculturalidade, as questões de gênero, as identidades culturais, as experiências sociais e seu papel na construção da cultura e da luta pelos direitos humanos.

\section{A HISTÓRIA DE ELIZA}

A história de Eliza, seu cotidiano, suas lutas dão vida à história presente de inúmeros imigrantes que habitam a cidade de São Paulo, nas últimas três décadas. Seu trajeto migratório, suas experiências no trabalho e, principalmente, suas batalhas diárias pela sobrevivência, na conquista de direitos e na luta contra o preconceito e a discriminação, dão corpo ao movimento social ativo na cidade, composto de múltiplas histórias entrecruzadas de sujeitos que se inserem na rede internacionalizada da produção têxtil paulistana.

Nascida na província de La Paz, em 1973, depois de ficar órfã de pai, foi abandonada pela mãe. O abandono, narrado por Eliza, resultou de um contexto repleto de preconceitos interconexos relativos às questões de gênero e etnia enraizados na sociedade boliviana. A mãe, que se autoproclamava de etnia branca, recusou a filha nascida de uma união com um descendente indígena, interessada, após a viuvez, em construir um novo relacionamento. Ao mesmo tempo, a mãe, segundo a interpretação de Eliza, sofreu discriminações com a situação da perda do companheiro por não ser casada oficialmente. Encontrando-se, em plena juventude, na situação de uma mulher sozinha, solteira e mãe de uma menina, ao visualizar a possibilidade de efetivar um novo casamento, optou pela entrega da filha à família do pai, e ocultou do novo marido a existência de Eliza "[...]quando eu fui conhecer ela com doze anos [...]" narrou a entrevistada:

[...]naquela época tinha muito preconceito com a mãe solteira, até aqui tem, em todo lugar tem preconceito, e quando ela ficou viúva do meu pai, ela não falou para meu padrasto que eu existia. Então quando eu conheci ela, o meu padrasto ficou sabendo e era uma surra atrás da outra para ela. Ela culpou para mim, ela falou que eu tinha culpa, mas eu não tinha culpa, porque eu não pedi para nascer. $[\ldots]^{1}$

De toda forma, a rejeição da mãe levou Eliza a ser criada entre os avós, tios e tias paternas. A menina se considerou órfã de pai e mãe até os doze anos de idade, quando soube da história e da existência de sua mãe "[...]por muito tempo pensei ser órfã de pai e mãe[...]" (disse Eliza), “[...]me criei com meus tios, e esses tios cada um da sua maneira me criou, claro que,

\footnotetext{
${ }^{1}$ Entrevista de 01 de outubro de 2010, em áudio e vídeo realizada no Diversitas-Núcleo de Estudos da Diversidade/FFLCH/USP. O nome apresentado no artigo trata-se de um nome fictício a pedido da entrevistada preocupada em preservar sua individualidade.
}

Revista de Direito Brasileira | São Paulo, SP | v. 17 | n. 7 | p. 154 - 164 | Mai./Ago. 2017 
sempre me orientaram do lado certo e isso eu continuo seguindo [...]. Foi na situação de uma família pobre, migrante da zona rural e envolta a dificuldades econômicas que Eliza foi criada por seus parentes paternos "[..] meus avós são do campo, meus bisavôs, também. Meus tios migraram para a cidade. Eu nasci na cidade La Paz, cidade satélite. Eu ia nas férias nas terras do meu avô, mas sempre morando na cidade, meus tios, eles não davam importância as terras do meu avô. Lá tem esse preconceito, da cidade e do interior [...]"2. Eliza estudou e completou o ensino fundamental, almejando estudar mais, seu desejo sempre foi estudar e se formar na faculdade:

[...] quando eu vim da Bolívia eu tinha estudado até a oitava série, eu estava ingressando no ensino médio, eu sentia querer estudar, eu sempre fui louca por estudo, eu queria ter tido a oportunidade, como meus primos, que tem uma vida mais estável. Eu acho, hoje em dia, que eu não tinha apoio, eu não tinha como, eu não podia, como eu não tinha mãe e pai eu sempre sentia que eles me criaram, mas não tinham mais obrigação de mim... já me deram muito até certa época. $[\ldots]^{3}$

Para além dos desejos e projetos individuais a situação na família sempre foi incomoda. Eliza vivia a condição de orfandade sempre como um incomodo, o incomodo de ser um peso financeiro aos avos, tias e tios. Neste momento da história de Eliza, a história individual da família, marcada pela cotidianidade como repetição constante do trabalho, dos hábitos e do costume se entrecruza com a grande história. Surge, no seio da família, uma proposta para a menina, então com 15 anos: trabalhar em São Paulo "[...] Aquela tia que deixou que eu viesse para cá, ela não tem muita instrução, então enganaram ela, falaram vamos fazer estudar e fazer trabalhar, e ela acreditou e, eu vim [...]". O nome não declarado do propositor revela a consciência atual da situação em que foi trazida ao Brasil e a São Paulo. Eliza e sua família sofreram a abordagem de um agente do tráfico de mão de obra boliviana às indústrias de confecção têxteis paulista. A promessa era a de trazer a adolescente para trabalhar e estudar em São Paulo, ficando sob a custódia deste agente, com acolhida em casa de família boliviana.

Foi desta forma que o projeto de emigração passou a fazer parte dos planos de Eliza. Naquele momento, sob a perspectiva da família em dificuldades financeiras e os dilemas individuais, a emigração surgiu como solução de problemas cotidianos. Eliza visualizou a viagem como um movimento em busca de oportunidades econômicas e culturais: um trabalho e a possibilidade de estudar, completar o ensino secundário.

Tratando da emigração como a outra vertente do processo imigratório, Sayad (1998) nos chama a atenção para o momento de construção do projeto de emigrar, um elemento do fenômeno da migração que compõe, complementa e atribui significados ao processo. Ainda como uma dimensão significativa, mas pouco refletida ou incorporada pela teoria migratória, o projeto de emigrar compõe-se da interligação das histórias individuais - fato individual - e os fatos coletivos, e assim foi com Eliza. A decisão de migrar é que produz, em primeira instância um emigrante, aquele que começa a conceber a possibilidade da mobilidade, uma vez que emigrar significa aceitar a ruptura de laços, ter coragem de deixar para traz diversos vínculos afetivos, familiares, somadas às referências culturais e espaciais de uma territorialidade local e nacional.

A experiência de Eliza, a partir daí se configura na intersecção de fatores da grande e da pequena história das migrações. A situação une certa tradição imigratória estabelecida entre Brasil-Bolívia, desde os anos 80, alimentada pela persistência e o funcionamento de uma rede ilegal de tráfico de mão de obra estabelecida entre a indústria de confecções paulistana e o

\footnotetext{
${ }^{2}$ Entrevista de 01 de outubro de 2010.
}

${ }^{3}$ Entrevista 01 de outubro de 2010. 
mundo, com as questões individuais, que envolvem desilusões familiares, a necessidade do trabalho, a vontade de estudar, a necessidade da independência financeira.

$\mathrm{Na}$ história de vida de Eliza nos deparamos diretamente com o agenciamento de mão de obra ilegal edificado em uma rede de recrutamento, transporte, subordinação e exploração da mão de obra. Desde a Bolívia, Peru e Paraguai, conta-se com uma estrutura que envolve agentes individuais aliciadores, emissoras de rádios e TV, jornais e agências de empregos ${ }^{4}$ responsáveis pela propagação e motivação das possibilidades de trabalho em São Paulo. Do primeiro passo, que é o agenciamento, a rede se direciona a um fluxo que alimenta um circuito de subordinação e exploração de mão de obra transnacional. Esse fluxo é delimitado em uma territorialidade internacionalizada e marcado pelos pontos de saída da mão de obra e destino de pessoas para a produção, circulação e consumo de mercadorias. Patarra (2006) considera que os movimentos e fluxos migratórios contemporâneos constituem claramente a contrapartida da reestruturação territorial planetária intrinsecamente relacionada à reestruturação econômico-produtiva em escala global $^{5}$. Desta forma consideramos as oficinas de costura e microempresas têxteis em São Paulo, que se tornaram o lócus do trabalho irregular, da subcontratação ou da escravização pura e simples de trabalhadores não-nacionais, configurando um território de instalação e permanência da mão de obra ilegal e do funcionamento das redes de adaptação e subordinação de indivíduos.

$\mathrm{Na}$ trajetória de Eliza, a decisão de emigrar a transformou em uma migrante internacional, vítima do tráfico de mão de obra, componente de uma cadeia produtiva internacionalizada da indústria têxtil. As projeções individuais do projeto migratório foram subvertidas pela lógica global do processo de exploração da mão de obra indocumentada no Brasil.

Foram 2 anos de permanência na oficina de trabalho sob a tutela de seu agenciador. A vida em São Paulo, numa casa-oficina, na zona norte - bairro Jardim Brasil - se resumia ao trabalho constante na costura e em afazeres domésticos, com longas jornadas diárias, quase nenhum descanso ou lazer. Além de uma condição vigiada de deslocamentos da oficina às ruas, sob o pretexto de que, sendo menor de idade e indocumentada, ela sofria um duplo risco com as autoridades brasileiras.

A única esperança de Eliza, entre seus 15 e 17 anos de idade, era a de que, ao menos uma das promessas realizadas se efetivasse: a possibilidade de cursar o segundo grau. Foram necessários dois anos, para que ela, de fato, visualizasse que a promessa nunca seria cumprida e que a situação na casa-oficina de costura não seria revertida, caso ela própria não tomasse atitudes drásticas.

Mesmo sem contatos na cidade, Eliza fugiu da oficina e se dirigiu ao bairro do Bom Retiro, no centro de São Paulo, com o intento de encontrar outros bolivianos e solicitar auxilio e acolhida de conterrâneos "[...]fugi, com a roupa do corpo e fui para a Estação da Luz porque me falaram que lá tinha muitos bolivianos[...]"6.

O fim do ciclo de confinação na oficina de costura não representou o fim das dificuldades em São Paulo, ao contrário, o desafio da Acolhida, como uma imigrante individual, se impôs como maior questão a ser resolvida. Como garantir moradia e trabalho como estrangeira indocumentada no Brasil, longe da rede da costura e, portanto, da rede de "acolhida"organizada e mantida pelo tráfico de mão de obra? Na verdade, a questão da acolhida se relaciona a problemas que envolvem o tráfico de pessoas, a configuração de um mercado de subcontratação de

4 "Reclutan gente joven para llevarla a trabajar como ilegal em San Pablo". La Razon. 18 de janeiro de 2011. Disponível em: <larazon.com/version.php.articled =125070\&Editionld=2431>. Acesso em: 4 abr. 2015.

5 PATARRA, NEIDE LOPES. Migrações internacionais: teorias, políticas e movimentos sociais. São Paulo: Estudos Avançados/USP. 20(57), 2006.

${ }^{6}$ Entrevista 29 de outubro de 2010 em áudio e vídeo realizada no Diversitas-Núcleo de Estudos da Diversidade/FFLCH/USP. 
trabalhadores e a constituição de um espaço urbano que alimenta a ilegalidade, a informalidade e a subcontratação num processo transnacional de exploração de mão de obra.

Como parte do processo migratório, em São Paulo, desde os anos 80, vem se estruturando um conjunto de redes sociais voltadas à ação direta com a população imigrante. Estas redes se estruturaram historicamente na sociedade contemporânea de forma globalizada e informatizada, articuladas às relações sociais de produção, segundo objetivos estratégicos e produzindo articulações locais que condensam formas organizacionais.

As primeiras dessas redes sociais foram constituídas a partir da ação de imigrantes (já sedimentados em bairros da cidade) e os empresários da costura, também imigrantes. Articuladas como estratégias de sobrevivência e subsistência econômica, organizaram-se por ações empreendidas entre imigrantes que auxiliavam conterrâneos no processo de recepção, adaptação e, paralelamente, por microempresários da costura e agenciadores de mão de obra, interessados em assentar, acomodar e subordinar a mão de obra subcontratada recém-chegada à cidade.

As redes sociais que envolvem imigrantes e estrangeiros nos permitem pensar sobre a complexidade da questão migratória em suas fronteiras políticas e simbólicas. Essas redes apresentam a face solidária da inserção do recém-chegado no novo espaço de instalação, trabalho e morada, mas, por vezes, revelam uma dimensão perversa do fenômeno, associando-se ao tráfico de mão de obra e à exploração do trabalho subcontratado.

No caso de Eliza, a primeira rede de recepção e acolhida foi organizada por imigrantes sedimentados como contratantes de mão de obra ilegal de conterrâneos. Desde a viagem, tutelada por traficantes de pessoas, Eliza se instalou na cidade sobre a frágil condição de indocumentada, desconhecendo a língua e o espaço físico e social, o que demarcava a dependência em relação ao empregador.

Uma vez livre da dependência e da condição subalterna, o desafio foi se inserir novamente como mão de obra e garantir suas necessidades mínimas. Novamente, a necessidade de sobrevivência na cidade a desloca para uma nova condição de subordinação, em troca de moradia e alimento. Na Estação da Luz o único contato que ofereceu abrigo a Eliza (após sua fuga) foi com uma comerciante brasileira, proveniente do Mato Grosso - também migrante, mulher e de descendência indígena - dessa forma confundida por todos (em São Paulo) com as bolivianas. Eliza descobriu uma afinidade entre ela (indígena boliviana) e a brasileira (de origem indígena) e ambas identificarem condições comuns se aproximaram.

Ao rememorar este momento, Eliza destaca a solidariedade da comerciante nacional e sua disposição em acolhê-la. Perceptivelmente, laços de afetividade acabaram por aproximar Eliza da nova empregadora, fazendo com que a situação, que novamente se assemelhava a subcontratação, com troca de trabalho por moradia e alimento, ressurja na memória como uma situação de acolhida e solidariedade.

Em meados dos anos 90, do emprego com o comércio de frutas na Estação da Luz, nossa personagem passou a outro, no comércio ambulante, agora acolhida na casa de uma boliviana que havia conhecido na Estação da Luz. Voltou ao círculo e ao convívio com bolivianos, e acabou por reencontrar seu antigo empregador. A amiga boliviana com quem trabalhava e que a abrigava, presenciando ameaças acabou por intermediar o contato de Eliza com o consulado da Bolívia. O Consulado a auxiliou no contato com a família, na obtenção de documentos bolivianos (que atestaram sua maioridade), e, no fim definitivo das perseguições do pretenso tutor boliviano, na verdade, o traficante de mão de obra.

Mesmo refazendo contatos familiares e tendo atingido a maioridade Eliza optou por permanecer no Brasil, não desejando voltar à Bolívia. Ao tratar desta opção, narra as dificuldades de readaptação à antiga vida familiar e um sentimento misto de orgulho e derrota que a levou a preferir manter a difícil condição no Brasil do que voltar a La Paz, sem haver mudado de condição financeira, sem haver conseguido estudar, sem haver conseguido juntar algum dinheiro que a pudesse promover socialmente em seu ciclo familiar e social. 
O sentimento de vergonha e derrota que não a permitia voltar demarcou a permanência no Brasil, como uma imigrante indocumentada, condição vivenciada por quase toda a década de 90. Eliza foi obrigada pelas circunstancias econômicas a voltar ao trabalho com a costura. Intenções de receber um pouco mais e ter moradia por conta própria levaram-na a procurar trabalho em pequenas oficinas têxteis. Foi neste momento, que descobriu como o trabalho indocumentado era algo recorrente em diversas oficinas da cidade, sem ao menos a necessidade de um agenciador, bastava procurar um emprego em oficina do Brás ou Bom Retiro que, mesmo sem documentos brasileiros ou carteira de trabalho haveria possibilidade de contratação.

Empregada novamente no circuito têxtil, Eliza circulou pela grande São Paulo, morando em diferentes bairros e até em outra cidade - Guarulhos - com diferentes pessoas, sempre em busca de moradia a preço acessível, melhores salários e melhores possibilidades de trabalho. Retomou seu antigo objetivo de estudar matriculando-se num curso supletivo da Avenida Tiradentes, no bairro da Luz. Trabalhava diariamente na costura e frequentava a escola noturna. Eliza considera este momento como um momento de ampliação do convívio com pessoas na cidade, no trabalho e na escola. Nesta fase construiu amizades, namorou e acabou por conhecer aquele que viria a ser o pai de sua única filha - um boliviano que trabalhava com vendas de máquinas de costura.

Novos desafios a Eliza - assumir a gravidez e a filha de forma independente - uma vez que o companheiro, que era casado, e, com mais 4 filhos, não poderia assumir os encargos da criança. Para nossa personagem a condição de imigrante, permanente condição de deslocamento territorial e social, marcada pelo distanciamento do ciclo familiar, se apresenta constantemente como uma condição de fragilidade e instabilidade do sujeito. A maternidade assumida sem nenhum apoio familiar, mesmo com a negativa de auxílio do companheiro demarca mais uma vez a situação cotidiana de Eliza e sua condição não apenas como mulher, mas como mulher migrante, deslocada e pressionada pela urgência da sobrevivência mínima. $O$ trabalho na oficina possibilitou a formação de uma rede de convivência apoiada em amizades e relações de vizinhança permitindo que Eliza conseguisse manter uma moradia e cuidasse de sua filha.

Em 1998, com 25 anos e residente há quase dez anos no Brasil, Eliza consegue participar da terceira anistia do governo brasileiro adquirindo o visto de morador provisório. A anistia e uma filha brasileira, nascida e registrada no Brasil alteram a condição legal de Elisa, oferecendo possibilidades concretas de trabalho regulamentado e, na visão da imigrante, aumentando possibilidades diferenciadas de trabalho em postos superiores da confecção ou do comércio, diante de sua escolaridade e suas capacidades individuais.

Neste momento, Eliza passou a perceber outros problemas não clarificados em sua experiência migratória, o preconceito puro e simples em relação ao migrante, à etnia indígena e à sua nacionalidade. Claramente, ela ouve diretamente de seu empregador uma negativa de promoção de cargo no trabalho da confecção. Elisa almejava trabalhar diretamente com as vendas ou assumir um cargo de gerência - o empregador reconhecia sua capacidade de trabalho, mas, reconhecia também as dificuldades em a promover diante das exigências dos consumidores ou mesmo dos trabalhadores da confecção que carregavam preconceitos e restrições em relação a questões de gênero e superiores hierárquicos que fossem indígenas e não nacionais.

Retorna à memória de nossa colaboradora toda sua experiência de vida desde a infância e adolescência na Bolívia, em sua história pessoal, o preconceito à etnia indígena marcou sua infância, afastando sua mãe e definindo a condição de orfandade vivida incomodamente em sua família paterna. As experiências com o preconceito retornam na idade adulta, como imigrante e mulher trabalhadora, quando reconhece a intolerância étnica, o xenofobismo e o machismo como limitadores de suas possibilidades profissionais:

[...]Por exemplo, numa firma onde eu trabalhei, com um coreano, trabalhei 4 anos com eles, trabalhei sai e voltei, eles me conheciam e sabiam que eu era 
muito capaz de várias coisas, a firma expandiu, tinha muitas pessoas experientes que eles podiam colocar em cargos, mas no primeiro dia que chegou uma loirinha eles colocaram ela de encarregada, eu pensei, poxa vida foi isso, se eu fosse loirinha eles iriam me colocar? Ele já me conhecia há anos, sabia do que eu era capaz, mas ele escolheu a loirinha. Elisa sabemos de sua capacidade, mas não dá! - Disse ele. Eu me senti muito mal. Na Bolívia também acontece. Veja a minha mãe, ela é clarinha e trata os fregueses como eu de qualquer jeito. Agora, quando aparece uma senhorinha bem vestida e branca, ela trata muito bem [...] a sociedade é cruel $[\ldots]^{7}$.

As questões que envolvem o preconceito, o racismo e a xenofobia reconhecidos na trajetória de Eliza, nos chamam a atenção para o campo da cultura e todo o conjunto de elementos simbólicos que compõem as imigrações laborais na contemporaneidade. De fato, no presente, as dimensões visíveis dos sujeitos não mais se encontram expostas clara e definidamente, gerando elementos identificáveis e de fácil categorização - a exemplo - o trabalhador não mais é um trabalhador e ponto, devemos encarar a questão de que um trabalhador ou trabalhadora pode se apresentar hoje como: um não nacional, indígena, indocumentado, semteto, e assim por diante. Elementos múltiplos compondo as cenas sociais, econômicas e políticas revelando uma exacerbação de questões da cultura e do lugar do sujeito como elementos centrais para a análise histórica.

Homi Bhabha (1998) tem chamado a atenção para algumas destas questões por meio de um termo o entre lugar - proposto como termo que defina a situação complexa do tempo presente e dos sujeitos múltiplos da globalidade que se apresentam diversos e difusos em suas demandas, características e identificações.

Como "entre lugar" podemos entender o momento em que, espaço e tempo se cruzam para produzir sujeitos complexos portadores simultâneos de diferenças e identidades, de elementos passados e atuais, da inclusão e da exclusão. Sob esta perspectiva, Elisa - imigrante, mulher, indígena, trabalhadora - ocupa o entre lugar. Um território da sobreposição de diferenças culturais, sociais e econômicas reconfigurado nas relações internacionais pela articulação de uma rede de trabalho internacionalizada latino-americana refletida na composição econômica da megalópole paulista.

Eliza migrou se instalou e, até hoje, sobrevive no território brasileiro neste difícil terreno do deslocamento identificado pelas negociações culturais constantes, pela sobreposição de diferenças, pela subordinação econômica dos sujeitos deslocados, pelos xenofobismos e racismos. Mas, ao mesmo tempo em que este entre lugar é marcado por sobreposições e subordinações, ele também se configura a partir das múltiplas possibilidades de representação, de aquisição de poder e de ação dos sujeitos nele instalados.

Nos espaços físicos de convivência simultânea na metrópole, na arquitetura das ruas e bairros, das oficinas de costura, das praças e locais de convivência se estabelecem as performances sociais dos sujeitos transformando, de fato, a cidade em um entre lugar de negociações culturais múltiplas. Sendo o sujeito àquele que pode ser visto, na cidade, como um elemento da diversidade, um trabalhador que integra um grande sistema internacionalizado e, também, um sujeito em suas performances individuais, sociais, culturais e políticas.

À guisa de conclusão, quanto à história de Eliza como sujeito migratório, podemos dizer que, sem dúvida o processo foi de conquistas de direitos políticos e econômicos. Eliza já não vive mais da costura, conquistou um espaço de trabalho e sobrevivência ligado à sua atuação política junto à comunidade boliviana e de seu bairro - o Bom Retiro. Desde que sua filha começou a frequentar a escola pública, Eliza passou a participar do Conselho de Escola (conselho deliberativo de gestão escolar no nível municipal e estadual) iniciando um exercício político de

${ }^{7}$ Entrevista de 01 de outubro de 2010.

Revista de Direito Brasileira | São Paulo, SP | v. 17 | n. 7 | p. 154 - 164 | Mai./Ago. 2017 
representação em seu espaço social. Esta condição lhe permitiu um novo olhar sobre sua própria situação de imigrante e sobre suas possibilidades de participação política na sociedade brasileira. Efetivou-se, na vida de Eliza, um encontro com a política, ou, ao menos, um encontro com possibilidade de se expressar, de opinar, de propor e participar de ações conjuntas para melhoria da escola local, da convivência entre bolivianos e brasileiros, da qualidade de ensino.

Da experiência no Conselho da Escola, Eliza ampliou suas ações e atuações passando a participar de agremiações e conselhos de outros aparelhos públicos como o Clube Escola (aparelho público municipal de recreação e lazer local). Hoje, atua como monitora de recreação do Clube Escola, sendo funcionaria de uma ONG que desenvolve projetos para crianças atendendo populações locais e bairros de carência econômica. Continua alimentando o sonho e a perspectiva que a fizeram mudar para São Paulo, poder estudar, fazer uma faculdade de pedagogia, "sua grande e maior vontade", nos diz Eliza.

Sobre sua situação atual, Eliza mantém expectativas futuras e a memória de uma luta empreendida para alcançar o direito de se expressar politicamente em espaços públicos institucionais de cidadania. Sob sua perspectiva, ela conquistou arduamente um espaço de expressão social e de trabalho comunitário. Iniciou sua luta como luta pela sobrevivência na cidade, continua empreendendo esta mesma luta, porém, com a ampliação para lutas comunitárias que envolvem a situação dos direitos sociais e humanos: o direito à educação, ao lazer e à convivência democrática em seu novo país. Uma filha de Eva, deslocada de seu lugar (o território nacional) recompôs sua história superando a condição de sujeito-sujeitado em busca da condição de sujeito-ativo.

\section{REFERÊNCIAS BIBLIOGRAFICAS}

BHABHA, H. O local da cultura. Belo Horizonte: Editora da UFMG, 1998.

PATARRA, N. L. Migrações internacionais: teorias, políticas e movimentos sociais. Caderno Estudos Avançados da USP, (57) [volume 20], 2006.

SARAMAGO, J. Caim. São Paulo: Editora Companhia das Letras, 2006.

SASSEN, S. Territory, Authority, Rigths. Princeton: University Press, 2008.

SAYAD, A. A Imigração ou os paradoxos da alteridade. São Paulo: Editora EDUSP,1998.

THOMPSON, E. P. A formação da classe operária inglesa: a maldição de Adão. Rio de Janeiro: Paz e Terra. [2a ed.], 1998. 